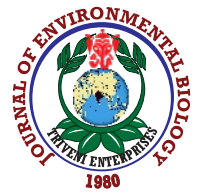

\title{
Phytochemicals with nanoparticles and their potential applications in medicine - A review
}

\author{
S.V. Rajith-Varman ${ }^{1,2}$, K. Baskar ${ }^{3 *}$, S.Y Kim ${ }^{4,5}$, M. Jayakumar ${ }^{6}$, M.V. Arasu ${ }^{7}$ and N.A. Al-Dhabi \\ ${ }^{1}$ Lab of Pharmacognosy, College of Pharmacy, Gachon University, \#191, Hambakmoe-ro, Yeonsu-gu, Incheon 21936, Republic of Korea \\ ${ }^{2}$ Harm Reduction Research \& Innovation Center [HRRIC], Mumbai-400 016, India \\ ${ }^{3}$ Department of Ecotoxicology, Ross Lifescience Pvt., Ltd, Pune-411 026, India \\ ${ }^{4}$ Gachon Medical Research Institute, Gil Medical Center, Inchon 21565, Republic of Korea \\ ${ }^{5}$ Gachon Institute of Pharmaceutical Science, Gachon University; \#191 Hambakmoe-ro, Yeonsu-gu, Incheon 21565, Republic of Korea \\ ${ }^{6}$ Department of Zoology, University of Madras, Chennai - 600025 India \\ ${ }^{7}$ Department of Botany and Microbiology, College of Science, King Saud University, P.O. Box 2455, Riyadh 11451, Saudi Arabia \\ *Corresponding Author Email : suribaskar@hotmail.com
}

\section{Abstract}

Phytochemicals having multiple properties which are used to cure various diseases such as cancer, diabetes, neurodegeneration, angiogenesis, aging, inflammatory, cardiovascular and arthritic disease, etc., Extensive use of phytochemicals and their derivatives leads to unavailability or scarcity of products in nature. Despite this episode, the nanotechnology resolves the setback of handling phytochemicals by increasing their bioavailability, longlost acting, target-specific and less or no toxicity. Here, we focused on the 24 known phytochemicals and preparation of NPs without discriminating the polymers and metals in NPs. All the phytochemicals did not fully satisfy the toxicological hazards, physical-pharmaceutical challenges, bioethical and health issues research. Hence these NPs and their NP incorporated phytochemicals need to be characterized in a way to give direct usage to the common man. Commercialization of NP formulations in pharmaceuticals needs statutory regulation norms for complete satisfaction and safety for endusers. As of now, many NP mediated pharmaceutical products are available in the market with full-fledged but still many unrevealed about their fate in the environment. In this review, the characterization of nanoparticles, the transparent benefit of nanoparticles (NPs), and their current application in various fields has been discussed.

Key words : Phytochemicals, Nano formulations, Nanomaterials, Toxicology regulation, Nanotechnology

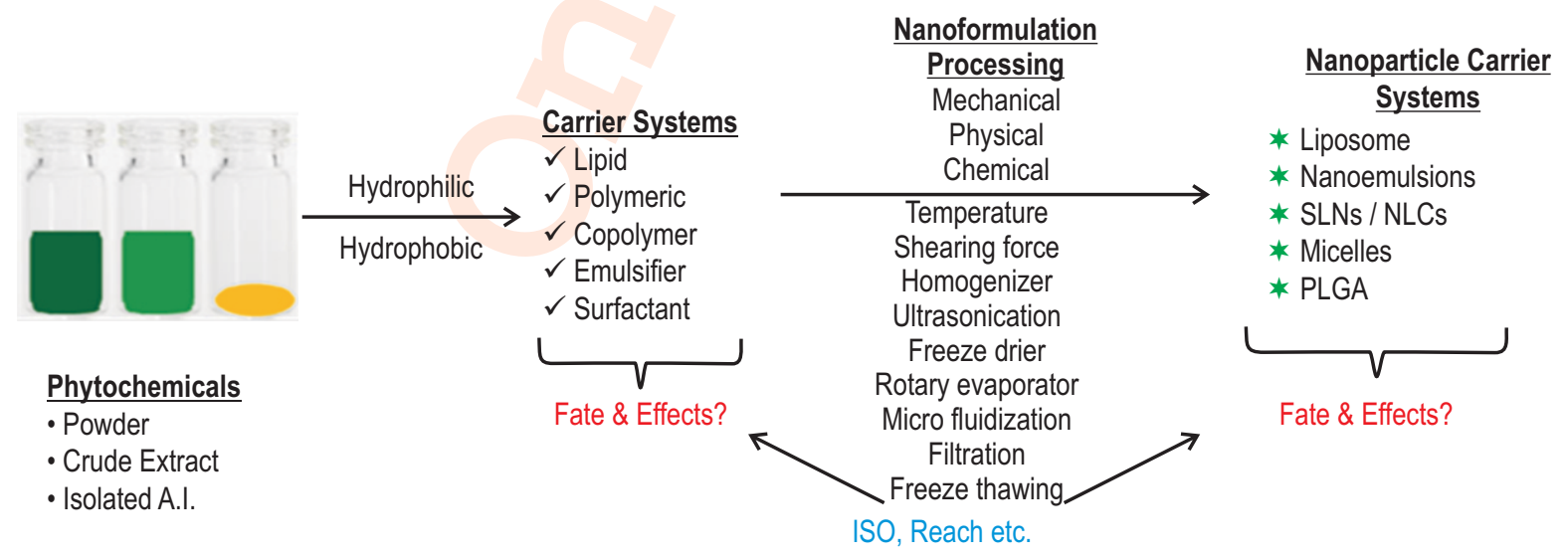

How to cite : Rajith-Varman, S.V., K. Baskar, S.Y. Kim, M. Jayakumar, M.V. Arasu and N.A. Al-Dhabi: Phytochemicals with nanoparticles and their potential applications in medicine-A review. J. Environ. Biol., 42, 918-929 (2021). 


\section{Introduction}

Phytochemicals are widely explored for their potential and promoting health benefits to humans for preventing many health issues. The abundant beneficial role of photo-chemicals toward mankind has been discovered in the field of nutraceutical, cosmeceutical, agrochemical, pharmaceutical and therapeutic (Venkatesan et al., 2015). Unlike synthetic drugs, there is limitation exists for the complete access of phytochemicals due to high cost, unstable, limited resource availability. In addition to that, low solubility, bioavailability problem, lack of targeted delivery system, and elevated toxicity are some other notable constraints (Azwanida et al., 2015). Even though phytochemicals are concealed with some unrevealed mysteries, these active molecules perceive major attention in vitro, in vivo, clinical research for the betterment of human beings (Venkatesan et al., 2015). Extensive phytochemical usage has become a major concern in the clinical implications. Many modern approaches emerge to solve the usage of phytochemicals, one of the promising areas of research is nanotechnology.

Nanotechnology is a controlled size carrier system at nanometer level with different sizes, shapes, composition, origin, dimension and widely used for industrial and biomedical activities. Nanomaterials (NMs) namely nanoparticles (NPs) and nonstructured materials (NSMs) size range between $1 \mathrm{~nm}$ to $1000 \mathrm{~nm}$ with different shape and source of origin (Wang and Wang, 2014). NMs are classified into 4 types based on the compositions (Bhatia, 2016), viz., Carbon-based NMs, Inorganic-based NMs, and Organic-based Nms and Composite-based NMs. NMs are also classified based on the source of origin as natural and Synthetic. Based on structure and shape, NMs can be classified into porous particles, sheets, fibers, wire and rods. Many nanoparticles have been selected based on the inert nature, biocompatibility, biodegradable, stability, low solubility and targetspecific properties. Further, NPs and NSMs possess different physicochemical properties such as stability, solubilization, catalytic activity, light absorption with scattering effect, electric and thermal conductivity (Ramalingam et al., 2018).

Natural NMs are produced by the action of biological species or indirect effect to humans on environmental pollution and pollutants (Narayan et al., 2018). Several methods are subjected for the preparation of nanoparticles such as mechanical, physical, and chemical processing or a combination of all above (Narayan et al., 2018). The suitability of NMs is solely based on biocompatibility and biodegradability in relevance to biology, biomedical application with less or no toxic nature. It includes polymeric biomolecules, lipid/phospholipid derivatives and metals (Blanco et al., 2015). Polymeric biomolecules, lipid, and phospholipids have gained beneficial application in many branches of therapeutics (Ahlawat et al., 2018). These lipid particles are considered as a better carrier system to enhance the efficacy of drugs/phytochemicals whereas the metals own their pros and cons. Also, the fucoidan polysaccharide coated manganese dioxide nanoparticles ( $\mathrm{MnO} 2$ ) have been efficiently used in the field of therapeutics for the suppression of tumor angiogenesis and is considered to be alternate for the hypoxic, radio resistant pancreatic cancer treatment (Shin et al., 2018). Minocycline is a potential candidate for neurological treatment that possess high therapeutic side effects because of its wide distribution and it has tailored with dendrimer NP conjugated significantly which improves the targeted drug delivery system (Sharma et al., 2017). Pharma products and synthetic chemicals have been extensively studied at different stages of research for regulatory norms (Wolff-Holz et al., 2019). In this review, the use of lipid particles at the therapeutics level by using formulations without discriminating other polymeric and metal NP's; liposomes, solid lipid nanoparticles (SLNs), nanostructured lipid carrier (NLCs) nanoemulsions, micelles, Poly (lactide-glycolide) (PLGA) nanoparticles is discussed.

Nanoparticles formulation: The synthesis of NPs depends on the purpose of its use, i.e., nutraceutical, cosmeceutical, agrochemical, pharmaceutical, and therapeutic fields (Pimple et al., 2012; Ahlawat et al., 2018; Elgohary et al., 2018). In special cases such as cancer therapy metals are required as core material for preparing nanoparticles. Circumstances alter the use of source or combination, generation of NPs utilizing natural or synthetic or combination of breakdown process or alteration of structural/ skeleton. Biocompatibility and bioavailability of phytochemicals play a major role in the health-based application; hence, NPs interplay with phytochemicals for the treatment of major deadly diseases (Blanco et al., 2015).

Liposomes are lipid bi-layer with outer hydrophobic and center hydrophilic compartments (Adamala et al., 2015). These nano-sized active molecules entangled between the hydrophobic membrane and hydrophilic position (Fig. 1a), induce the targeted delivery in contact with specific moiety formulations, enhance the half-life $\left(\mathrm{t}^{1} / 2\right)$ period and are released in a sustained manner (Alvarez-Arellano et al., 2020).

Hydrophobic lipid molecules dispersed in hydrophilic liquid moiety form nanoemulsions (Jain et al., 2013). The hydrophobicity nature of lipid forms a separate layer, due to surface tension of aqueous and lipid molecules (Fig. 1b) (Han et al., 2012; Argenta et al., 2014). This phenomenon has been overcome by the surfactant or emulsifier, amphiphilic nature, reduced surface tension between two moieties and distributes the lipid droplets in an even manner (Klumphu et al., 2014). This effective emulsion can be used for a wide range of application in the field of drug delivery system, such as hydrophobic vitamins (A, D, E, and K), omega-3 fatty acid, carotenoids, and many other hydrophobic drugs (Jain et al., 2013; Chen et al., 2018). Some common physical and chemical methods such as sonication, homogenization, and microfluidization are required to synthesize nanoemulsion. 
A novel carrier system, with a hydrophilic center core surrounded by solid lipid core with or without surfactant, has several benefits such as greater stability, reduction in the loss of active molecules, and targeted/sustained release than traditional nanoemulsion (Oehlke et al., 2017). Poorly, soluble hydrophobic compounds, such as lipid-soluble vitamins, resveratrol, curcumin, etc., require site targeted delivery system like solid lipid nanoparticles (SLNs)/Nanostructured lipid carriers (NLCs). These carrier systems are encapsulated along with surfactant for a uniform nanoemulsion. The prepared nanoemulsion (SLNs/NLCs) is polymerized with the gelatin/ trehalose/ chitosan/ silica/starch for surface-modified drug delivery system to targeted site release (Fig. 1c) (Jain et al., 2013; Pandey et al., 2015; Ngwabebhoh et al., 2018). SLNs/NLCs are generated by physical and chemical methods with high-speed shearing force, homogenization, ultrasonication, and hot plate with stabilizer.

Micelles (Nps) are commonly used in the parenteral route, oral, ocular, and topical administration of pharmaceutical products. The micelles (Nps) preparation needs the following techniques such as rotary vacuum evaporator, freeze-drying, ultrasonication, and controlled temperature shearing force. The micelles capture a prominent place in the lipid-based carrier system. It is an amphiphilic-colloid formed by lipid (stearic acid). The phospholipids NPs accommodate hydrophobic compounds within the fatty acid core part. Micelles were produced at the optimum temperature where amphiphilic phospholipids underwent polymerization with drug/phytochemical and entraps in the shell core (Yan et al., 2017). During polymerization, the micelles macromolecules have irregular shape and size. NPS are further trimmed to less than $50-100 \mathrm{~nm}$ by physical methods (Fig. 1d) (Panpipat et al., 2013). In situ study, toll-like receptor (TLR) agonist (R848) nano micelles formulation efficiently, activates antigen-presenting cells (APC) (Kim et al., 2018).

Glycolic acid and lactic acid are polymerized to form Poly (lactic-co-glycolic acid) (PLGA) NPs (Andima et al., 2018). During polymerization, the drug/phytochemical is encapsulated to form a hydrophobic emulsion in the hydrophilic phase (Pimple et al., 2012), further evaporated to leave hydrophobic phase with entrapped phytochemical /drug (polymerized PLGA drug) of varied size (Fig. 1e). PLGAs are freeze-dried, followed by

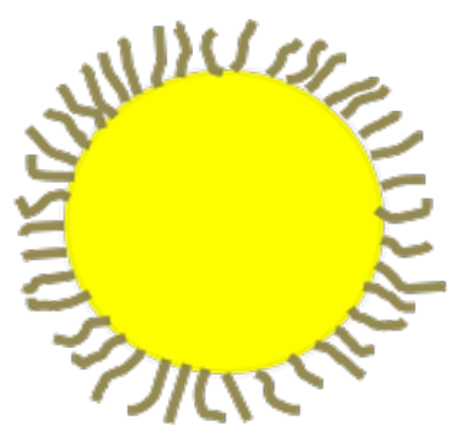

(a)

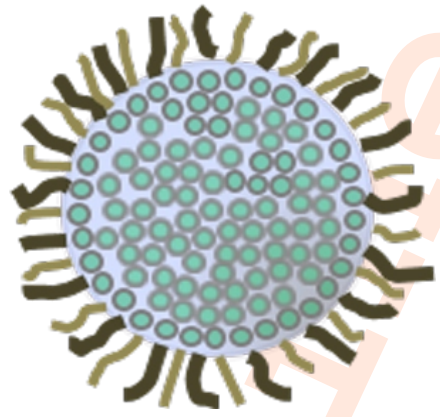

(b)
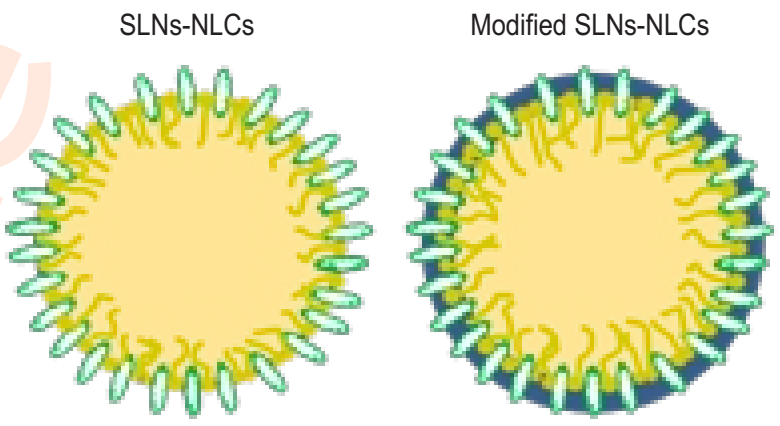

(c)

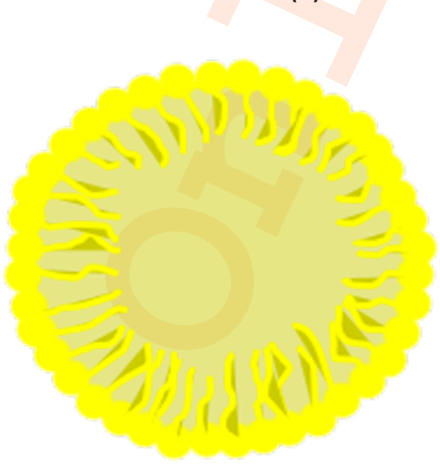

(d)

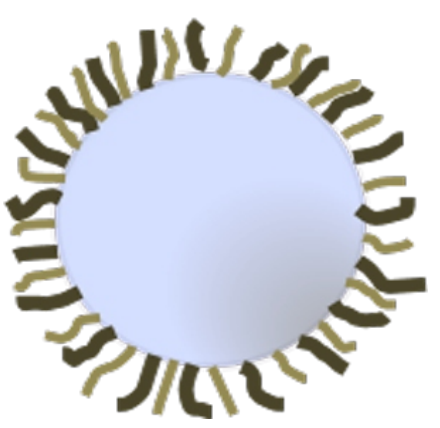

(e)

Fig. 1 : (a) Liposome consist of outer hydrophobic and inner hydrophilic core with water soluble drugs; (b)Nanoemulsion, the hydrophobic moiety surrounded by hydrophilic liquid phase; (c) Solid-lipid Nanoparticle/ Surface Modified Solid-lipid Nanoparticle contains hydrophilic center core surrounded by lipid core with or without surfactant; (d) Micelles, an amphipathic nature contains both hydrophilic head region and hydrophobic tail portion; (e) Poly (lactic-co-glycolic acid) is a hydrophilic nature, copolymer of glycolic acid and lactic acid used for polymerization with hydrophobic to give emulsion. 
ultrasonication to get NPs of PLGA (Pimple et al., 2012; Das et al., 2013). The FDA-approved PLGA-drugs are used for human cancer therapy (docetaxel, everolimus) and nutraceuticals (Vitamins, Folic acids, phytochemicals - Ferulic acid, Ginsenoside Rg3) (Lima et al., 2018). It is also used as biomolecules (proteins, siRNA, DNA) (Zhang et al., 2017; Singh et al., 2017), biocides (antibiotics) (Liu et al., 2018) for various infections. PLGA drugloaded NPs are widely used in the oral, parental and topical route of administration (Chan et al., 2017).

Characterization of NPs: Some of the important parameters used for the pharmacological and commercialization of Nps are particle size, surface charge, chemical, homogeneity, stability, agglomeration, and morphology. Establishing the NPs characterization based on the major features of properties are as follows.

To determine the fitness of nano molecules, the particle size of NPs is considered mandatory. The colloidal, particulate, and molecular characterization of NPs is determined by Dynamic Light Scattering (DLS), SEM analysis, and Zeta Potential Analyzer (Abd-Rabou et al., 2017). The characterization is done by the magnitude of electrical charge, distribution, and molecular weight (Bhatia, 2016; Narayan et al., 2018). Usually, high zeta potential provides high stability to NPs. DLS is able to determine particle size range from $250 \mathrm{~nm}$ to $6 \mu \mathrm{m}$ whereas zeta potential analyzer determines particle size starting from $1 \mathrm{~nm}$ to $100 \mu \mathrm{m}$. The molecular weight of NPs prominently fall in the range between 1 to $25 \mathrm{MDa}$.

The surface charge present on the NPs by placing them in a liquid indicates the magnitude of electrostatic repulsive action between NPs (Bhatt et al., 2015; Bhatia et al., 2016). The higher value of surface charge is considered to be stable NPs. If the zeta potential is lower irrespective of $(+)$ or $(-)$, the NPs tend to aggregate to form clumps, such NPs arbitrator deprived quality with uneven particle size.

The characterization of NPs at specific wavelength shows scattering property, usually at visible (700 to $400 \mathrm{~nm})$ and ultraviolet (UV) region (400 to $250 \mathrm{~nm}$ ). Generally, NPs being smaller in particle size are scattered in the red region (i.e. UV region) (Sun et al., 2014; Sapino et al., 2015). The molecules of NPs absorbs spectral energy and gets excited to give $\lambda$ max at different wavelength. In similar fashion, the drug/phytochemicalloaded NPs tend to change the absorbance after excitation..

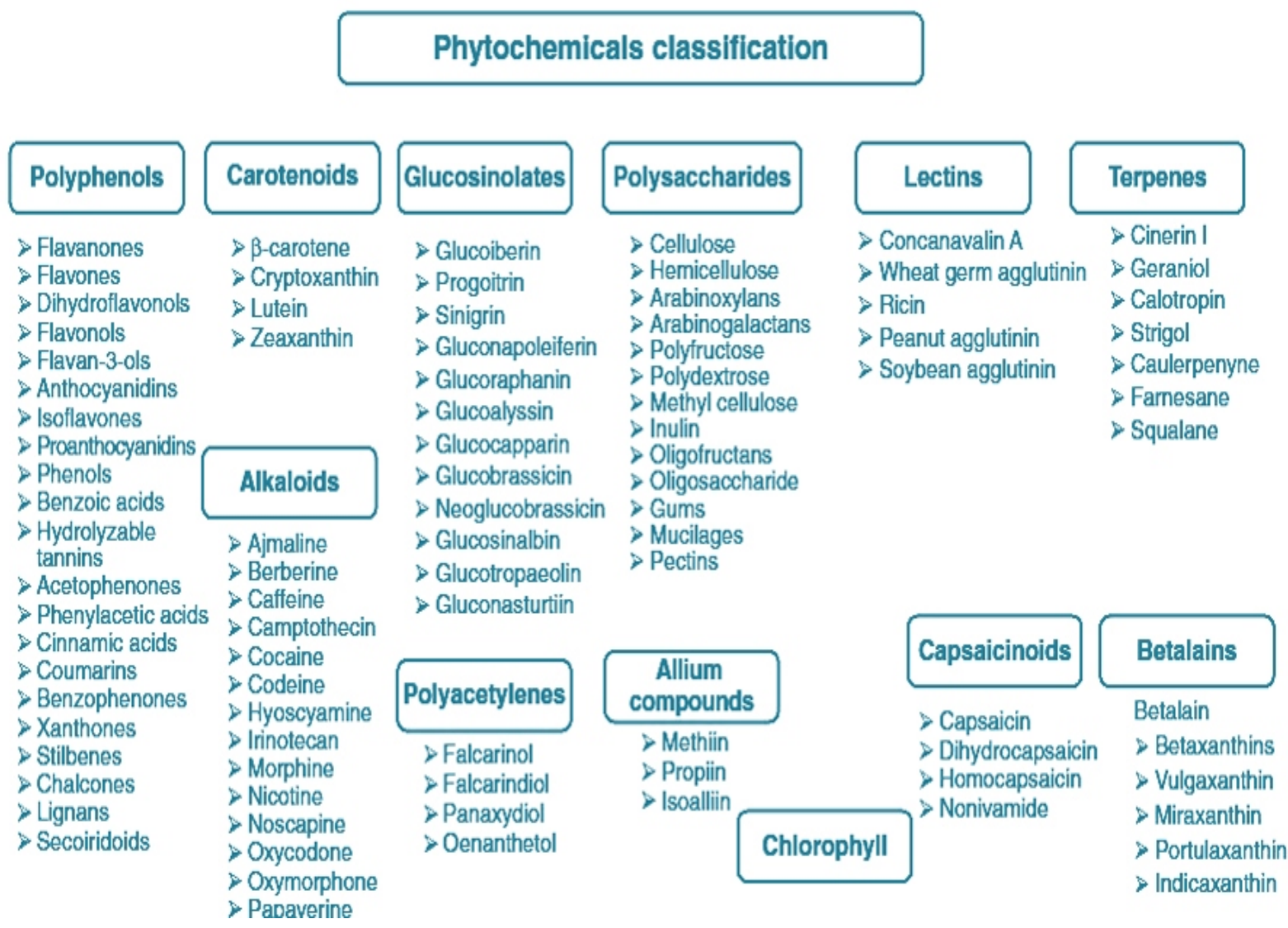

Fig. 2 : Phytochemicals classification based on their group. 
NPs in the aqueous medium tend to aggregate or disperse evenly depending on the surface charge and electrostatic effect (Je et al., 2017). This property of NPs has advantage of delivering the drug/phytochemicals at a specific $\mathrm{pH}$ medium (Sapino et al., 2015). The surface-modified SLNs release the drug at optimum acidic $\mathrm{pH}$ in the stomach and sustainably release the drug in the small intestine with the help of bile acid action. Oehlke et al. (2017) reported that ferulic acid and tocopherol enhanced stability and encapsulation efficacy revealed better bioavailiblity in the system.
The properties (targeting and loading) of nanoformulation vary, based on their bonding factor (weak or strong) of the drug in nanomaterials (Ngwabebhoh et al., 2018) NPs in surface charged and homogeneous particle size contribute to high stability of NPs in the medium (David et al., 2015). NP with the surface positive charge coated formulation injected intravenously results in resistant absorption to plasma proteins which limits opsonization (Chen et al., 2018). On opsonization, the availability of NPs in the blood stream consequently falls or are removed by the macrophagic action (Sun et al., 2014). Hence, the surface

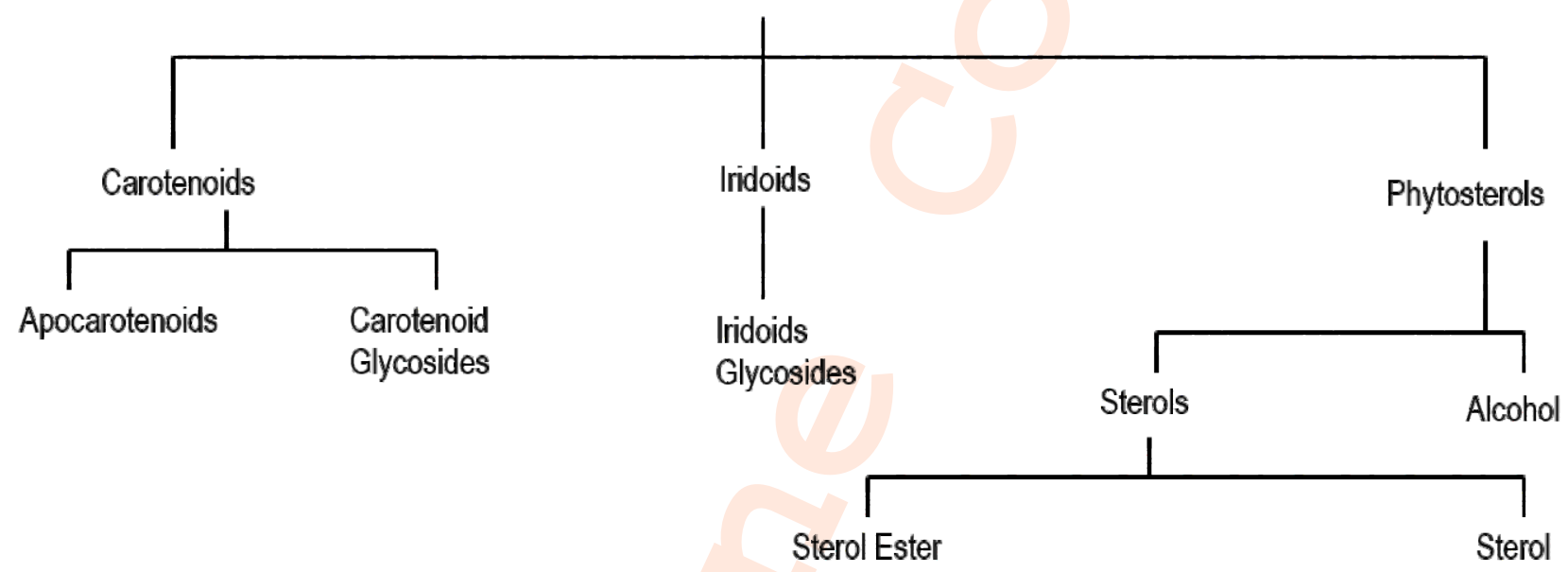

b

Phytochemicals

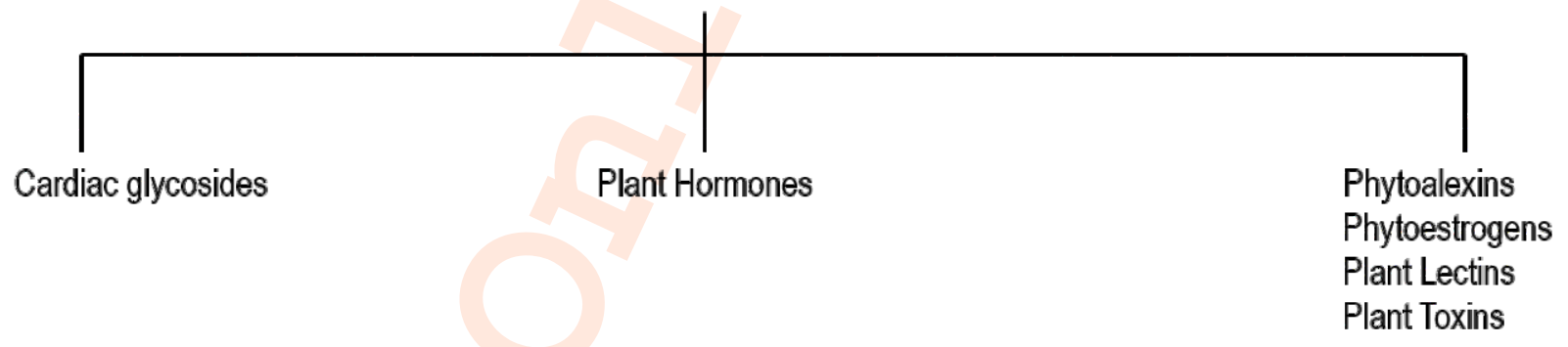

C

Phytochemicals

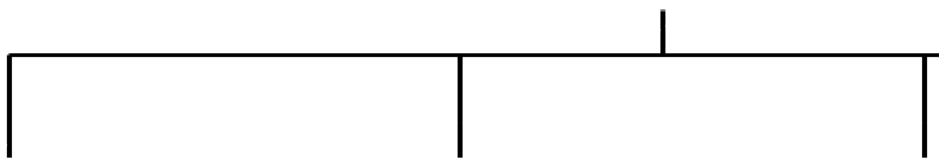

Polyphenols

Terpenes 


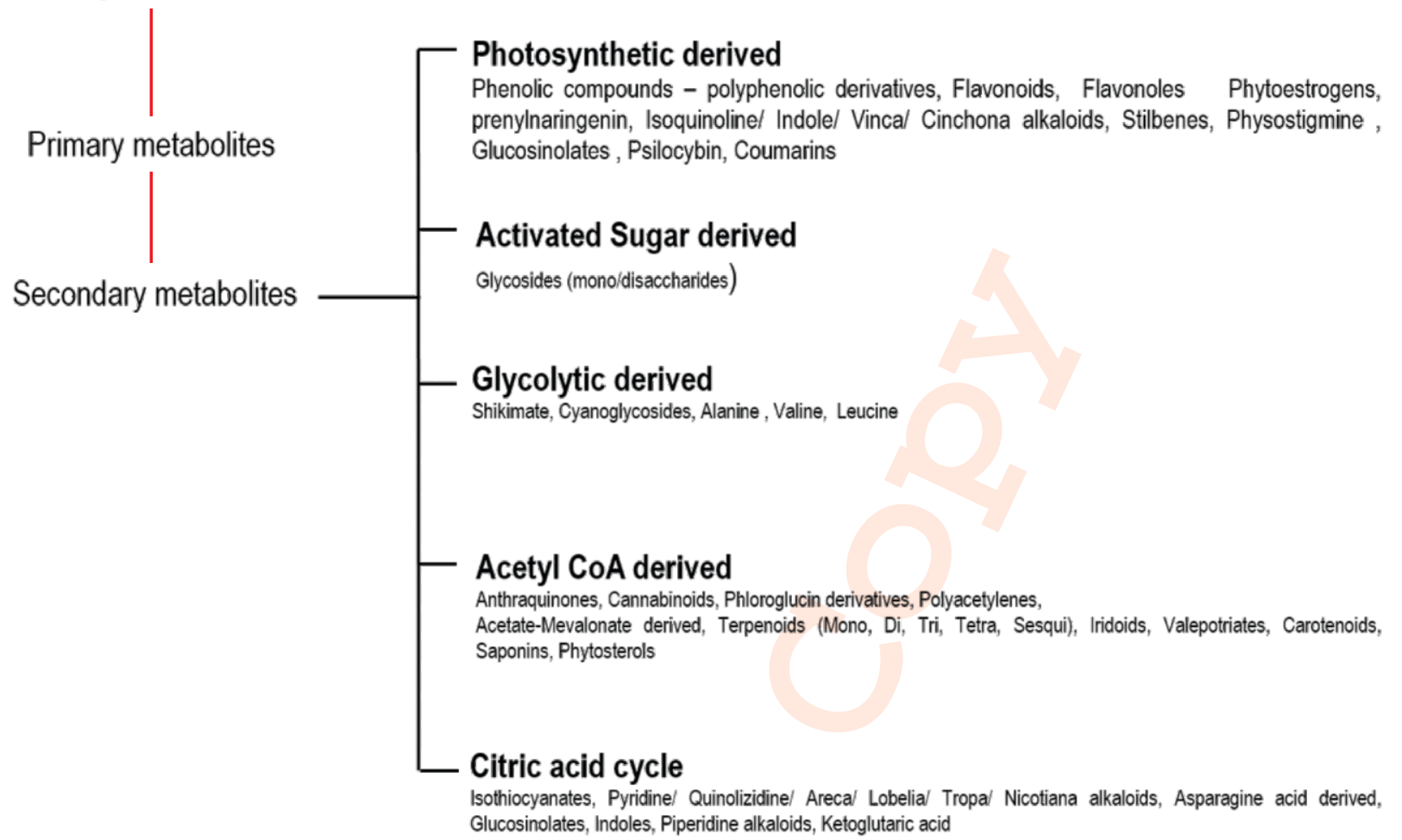

Fig 3: Schematic representation of classifications. a) Based on chemical structures; b) Based on physiological functions; c) Based on Taxonomy; d) Based on Biosynthesis and Biological Functions.

modification of NPs increases the half-life time in the body which can be used as an important parameter to enhance or improve the efficiency of NPs.

Encapsulation shows the increasing potential of NPs and the efficiency of entrapment of drugs/compound/ nutrients are termed as a percentage of drug entrapped/absorbed into NPs (Jain et al., 2013). For instance, the microemulsion NPs generated by the addition of oil in water with surfactant, eventually dispersed in to layer in water (Singh et al., 2014). The micelle NP in the aqueous phase can allow the fusion of nonpolar molecules. The percent entrapped drug/ molecules in micelles can also describe as total drug added to NPs and the availability of free non-entrapped drug divided by total drug added is named as encapsulation efficiency (EE\%) (Sharma et al., 2015; RezaeiSadabady et al., 2016).

NPs have the capacity of retaining the drug/ molecules within the final finished formulation. In the case of lipid nanoparticles, especially SLNs show high drug loading capacity. The efficiency of loading capacity is calculated by assessing the drug release from the final product of drug incorporated-NPs when exposed to the liquid phase and agitated for a specific time of incubation (Li et al., 2018).

Phytochemicals : Phytochemicals, non-nutritive plant-sourced bioactive molecules, comprise of a diverse chemical group. It has multiple roles in the plant to protect from environmentally hazardous jeopardy, such as pollution, UV light, pathogenic attack, drought, stress, antioxidant, detoxifying agent, immunebooster, hormonal modulator, and anticancer (Venkatesan et al., 2015). Plants have secondary metabolites possess the repellent/toxic potential to insects, similarly plant chemicals also traps prey by attractant chemicals (Guo et al., 2018). The protective role of phytochemicals/ vegetables, fruits, and their derivatives against cancer, oral, pharynx, oxidative stress, endometrium, heart disease, stomach, esophagus, pancreas, and colon perceive attention has been clearly emphasized by Li et al. (2015).

Based on the protective property and beneficial effect, phytochemicals escort substantial invade to promote a healthier lifespan to human. A wide variety of phytochemical existence leads indistinguishable by many research groups for better classification (Fig. 2). Phytochemicals are mainly categorized based on the chemical structure, physiological function, 
taxonomy, biosynthesis and biological functions. But each classification of phytochemicals carries their benefit to pin-up all the phytochemicals that fall in their category (Mukkavilli et al., 2017).

Based on the chemical structures, phytochemicals are classified into (i) carotenoids followed by apocarotenoids, carotenoids, and glycosides, (ii) iridoids further with iridoid glycosides and (iii) phytosterols by stanols, sterols ester, and sterols alcohol. Schematic representation of chemical structurebased classification is given in Fig. 3a. Based on the role of phytochemical exhibited in the host/ beneficiary system, the phytochemicals are classified as (i) Cardiac glycosides, (ii) Plant hormones, and (iii) Phytoalexins, which are further classified as phytoestrogens, plant lectins, and plant toxins. Classification based on physiological functions is shown in Fig. 3b. Phytochemicals are categorized based on the source of evolution/taxonomy; They have been classified into (i) Alkaloids, (ii) Glycosides, (iii) Polyphenols, and (iv) Terpenes. Taxonomically categorizing the phytochemicals is considered to be simple, broad and covers all phytochemicals (Fig. 3c).

Phytochemicals are classified into two categories as primary and secondary metabolites from the source where the phytochemical originated in the plant as a precursor of the bioactive molecule (Azwanida et al., 2015). Primary metabolites are carbohydrates, amino acids and lipids, which are broken down or gets converted into secondary metabolites due to the action of stress, stimulator, pollution, etc. (Fig. 3d). This classification based on biosynthesis and biological functions has gained wide acceptance but still prevails conundrum.

Therapeutically oriented phytochemicals and nanoparticle application : Many traditional sourced plants and crude extracts hold enormous phytochemicals of primary and secondary metabolites. Phytochemicals, a plant bioactive molecule acts as substrates, cofactors, inhibitors, absorbent/sequestrant, ligand, scavenger, enhancer, stabilizer and growth promoter with potential health and environmental benefits to human, animals and plants (Venkatesan et al., 2015). Polyphenols are usually stable in acidic $\mathrm{pH}$ but get degraded in neutral and weak alkaline environments of the small intestine and bloodstream (Kim et al., 2018; Borges et al., 2020). Ginger extract and its constituents (6gingerol, 6-shogaol, 6-paradol, zingerone and dehydrozingerone) have shown beneficial effects in neuropathological conditions (Choi et al., 2018). Collagen preparations possess beneficial effects on skin elasticity, moisturizing and controlling aging factors such as wrinkle formation by increasing the expression of hyaluronic acid synthases (HAS-1 and 2) (Kang et al., 2018).

Many research groups have intensively paid attention to renowned phytochemicals for NP formulation and created sufficient toxicological profile data from in-vitro and in-vivo levels.
Phytochemicals such as quercetin, resveratrol, curcumin, apigenin, kaempferol, epigallocatechin gallate, berberine, genistein, gikgolide are being used for nano formulation (Hussein et al., 2018; Mirhadi et al., 2018; Penalva et al., 2018; Pool et al., 2018). Similarly, the hydrophobic zein-phosphatidylcholine liposome NP is considered to be an effective and promising carrier system for many drugs like paclitaxel, docetaxel, celecoxib and curcumin (Lou et al., 2019). Considering this hypothesis, many NPs have been synthesized to achieve better bioavailability, sustained release and target-based release of phytochemicals.

Recognized phytochemicals subjected for nanoformulations reported significant/ insignificant number of studies to prove for various therapeutical beneficial effect. Few phytochemicals fails to reach attention for NP formation eg. lactucopicrin, gnetol, honokiol, magnolol and spicatoside A.

PEG conjugated NP targeted release of quercetin to cancer cells has been confirmed by in-vivo and in- vitro studies (El-Gogary et al., 2014). Similarly, targeted brain delivery of quercetin-SLN's formulation (Naqvi et al., 2020) and PLGA-NPs co-encapsulated quercetin, tamoxifen increased bioavailability for better efficacy against DMBA-induced breast cancer in Sprague Dawley rats (Jain et al., 2013). NP formulation using silica, chitosan, poly-lactic acid and liposomes of quercetin is considered to be an effective treatment against anti-cancer, antiAlzheimer's disease by exhibiting quercetin properties of regeneration, prophylaxis and neuroprotection (David et al., 2015; Sharma et al., 2015; Li et al., 2015; Pandey et al.,2015; Rezaei-Sadabady et al., 2016).

Resveratrol, a proven stilbenoid effectively controls free radicals, microbes, cardiovascular disease (CVD), neuro/ inflammatory mediators, hepatotoxic, skin dryness diabetics, dyslipidemia, cancer (Montenegro et al., 2017; Serini et al., 2018; Shen et al., 2018). Numerous studies have been done with the formulation of NPs in vitro, in vivo and clinical level using Trimethyl chitosan (TMC), Chitosan PLGA, PEG, Dextran, CMC, protein-based NP (casein, OVA, hyaluronic acid, BSA, Sericin, lactalbumin), lipid-based NP formulations (linolenic acid, stearic acid, Phosphatidylcholine, oleic acid, PUFA), silica-based NPs, etc. (Fachinetti et al., 2018; Guo et al., 2018; Penalva et al., 2018; Suktham et al., 2018).

Curcumin nano-formulation using Hyaluronic acid, Chitosan, Protein-based NP (BSA, Zein), lipid-based NP (Bean oil), PEG, PLGA, Cellulose-based formulation has proved to be a promising treatment for free radical, inflammatory, cancer, microbial, CVD, hepatotoxicity, diabetics, dyslipidemic, arthritic, obese and neurological disorders (Ghaffari et al., 2018; Camargo et al., 2018; Malvajerd et al., 2019; Mukherjee et al., 2019; Mohammed et al., 2019). Similarly, other hydrophobic phytochemicals such as apigenin (Ding et al.,2014; Karim et al., 
2017; Pal et al., 2017; Papay et al., 2017), kaempferol (Tzeng et al., 2011; Luo et al., 2012; He et al., 2014; Ilk et al., 2017; Hussein et al., 2018), epigallocatechin gallate (Chamcheu et al., 2018; Tang et al., 2018; Kuhne et al., 2019), berberine (Park et al., 2015; Allijn et al., 2017; Mirhadi et al., 2018; Wang et al., 2018; Buchanan et al., 2018), gingerol (Behroozeh et al., 2018; Khoshnevisana et al., 2018; Hwang et al., 2018), naringenin (Ji et al., 2016; Wang et al., 2017; Parashar et al., 2018; Singh et al., 2018), catechin (Naponelli et al., 2017; Sistanipour et al., 2018; Ahmad et al., 2019), ellagic acid (Mady et al., 2017; Fahmy et al., 2018) owns their health benefits to humans relatively equal to curcumin, resveratrol and quercetin which studied well by using many NP formulations. Nano-formulations are protein/ glycoprotein-based, lipid-based, silica-based, phospholipidbased, carbon-based, chitosan-based, polysaccharides-based nano-formulation prepared and studied at various levels to prove health benefits to mankind. Many phytochemicals exhibit enormous health benefits as individual entities or formulated with NPs without/minimal toxic property.

In this review, the nanoparticle formulation, characterization, evidence of phytochemicals with nanotechnology and their application in health benefits are discussed. These phytochemicals are gingerol, naringenin, catechin, ellagic acid, huperzine $A$, silymarin, $\beta$-sitosterol, and ferulic acid (Lee et al., 2017; Hong et al., 2018; Abdel-Wahhab et al., 2018; Ponnulakshmi et al., 2019). According to Kim et al. (2006) investigation on naringin has a beneficial role in lowering the hepatic cholesterol level in SD rats. NP formulated on naringin is yet to be investigated for their beneficial role in the treatment of hyperlipidemic patients.

Very few nano-formulations have been prepared and studied for phytochemicals such as genistein (Nguyen et al.,2015; Jackson et al., 2017; Kim et al., 2017; Pool et al., 2018), rosmarinic acid (Madureira et al., 2016; Ezzat et al., 2016), huperzine A(Meng et al., 2018), ginkgolide (Feng et al., 2018; Lou et al., 2019), ginsenoside (Kim et al., 2016; Aalinkeel et al., 2018; Dai et al., 2018) and ß-Sitosterol (El-Nahas et al., 2017; Gogoi et al., 2018; Ponnulakshmi et al., 2019). As stated, few phytochemicals are not synthesized as a nanoformulation (Venkatesan et al., 2016, Venkatesan et al., 2017, EncinasBasurto et al., 2018, Hosokawa et al., 2018; Sarrica et al., 2018). Additionally, reviewed the regulatory perspective of registry for the NPs focused in streamlining the synthesis and the NPs disposal norms (Weiss-Angeli et al., 2012; Hansen et al., 2017; Zainon and Azmi, 2021).

Phytochemicals and their health benefits has infiltrated modern science and nanotechnology to fulfill the needs of new drug development in medicine. Many phytochemical applications bottlenecked for complete contribution to health and utility because of characteristic properties. Due to the advancement of nanotechnology, the hinderace can be overcome by formulating the phytochemicals with the nanoparticles. This enhances the merging of ethnobiology and nanotechnology to provide health benefits to mankind through nanomedicine field. This nanomedicine has many advantages at therapeutic level such as better solubility, low toxicity, biocompatibility, enhanced half-life, modifiable surface interaction and target-based release.

Even though lots of advancement in the drug delivery system are available, there are still significant gaps prevailing for complete access to nanomedicine without proper regulation. Nanomedicine needs multiple criteria to get passed such as insilicon, in-vitro, in-vivo preclinical and clinical trials. As of now, NPs registration prepared is based on the biodistribution alone but not based on toxicity profiling. Vast advancement in NPs registration needs further classification or broad information of risk assessment, handling and control over NPs application to the environment and human health.

\section{Add-on Information}

Authors' contribution: S.V. Rajith-Varman, K. Baskar: Objective and original revision of article prepare; S.Y Kim, M. Jayakumar, M.V. Arasu and N.A. Al-Dhabi: Review and improve earlier, revision of article.

Research content: The research content of manuscript is original and has not been published elsewhere.

\section{Ethical approval: Not applicable}

Conflict of interest: The authors declare that there is no conflict of interest.

\section{Data from other sources: Not applicable}

Consent to publish: All authors agree to publish the paper in Journal of Environmental Biology.

\section{References}

Aalinkeel R., H.L. Kutscher, A. Singh, K. Cwiklinski, N. Khechen, S.A. Schwartz, P.N. Prasad and S.D. Mahajan: Neuroprotective effects of a biodegradable poly(lactic-co-glycolic acid)-ginsenoside Rg3 nanoformulation: A potential nanotherapy for Alzheimer's disease?. J. Drug. Target., 26, 182-193 (2018).

Abdel-Wahhab, M.A., A.A. El-Nekeety, A.S. Salman, S.H. Abdel-Aziem, F.M. Mehaya and N.S. Hassan: Protective capabilities of silymarin and inulin nanoparticles against hepatic oxidative stress, genotoxicity and cytotoxicity of deoxynivalenol in rats. Toxicon., 142, 1-13 (2018).

Abd-Rabou, A.A. and H.H. Ahmed: CS-PEG decorated PLGA nanoprototype for delivery of bioactive compounds: A novel approach for induction of apoptosis in HepG2 cell line. Adv. Med. Sci., 62, 357-367 (2017). 
Adamala, K., A.E. Engelhart, N.P. Kamat, L. Jin and J.W. Szostak: Construction of a liposome dialyzer for the preparation of highvalue, small-volume liposome formulations. Nat. Prot., 10, 927938(2015).

Ahlawat, J., G. Henriquez and M. Narayan: Enhancing the delivery of chemotherapeutics: Role of biodegradable polymeric nanoparticles. Int. J. Molecules., 23, 2157 (2018).

Ahmad, M., P. Mudgil, A. Gani, F. Hamed, F.A. Masoodi and S. Maqsood: Nano-encapsulation of catechin in starch nanoparticles: Characterization, release behavior and bioactivity retention during simulated in-vitro digestion. Food Chem., 270, 95-104 (2019).

Allijn, I.E., B.M.S. Czarny, X. Wang, S.Y. Chong, M. Weiler, A.E. da Silva, J.M. Metselaar, C.S.P. Lam, G. Pastorin, D.P.V. de Kleijin, G. Storm, J.W. Wang and R.M. Schiffelers: Liposome encapsulated berberine treatment attenuates cardiac dysfunction after myocardial infarction. J. Control. Rele., 247, 127-133 (2017).

Alvarez-Arellano, L., M. Salazar-García and J.C. Corona: Neuroprotective effects of quercetin in pediatric neurological diseases. Molecules, 25, 5597 (2020)

Andima, M., G. Costabile, L. Isert, A.J. Ndakala, S. Derese and O.M. Merkel: Evaluation of beta-sitosterol loaded PLGA and PEG-pla nanoparticles for effective treatment of breast cancer: preparation, physicochemical characterization, and antitumor activity. Pharmaceutics., 10, 232 (2018).

Argenta, D.F., C.B. de Mattos, F.D. Misturini, L.S. Koester, V.L. Bassani, C.M.O. Simoes and H.F. Teixeira: Factorial design applied to the optimization of lipid composition of topical antiherpetic nanoemulsions containing isoflavone genistein. Int. J. Nanomed., 9, 4737-4747 (2014).

Azwanida, N.N.: A review on the extraction methods use in medicinal plants, principle, strength and limitation. Med. Aromat. Plants., 4, (2015). DOI: 10.4172/2167-0412.1000196

Behroozeh, A., M.M. Tabrizi, S.M. Kazemi, E. Choupani, N. Kabiri, D. Ilbeigi, A.H. Nasab, A.A. Khiyavi and A.S. Kurdi: Evaluation the anti-cancer effect of PEGylated nano-niosomal gingerol, on breast cancer cell lines (T47D), in-vitro. Asian Pac. J. Cancer Prev., 19, 645-648 (2018).

Bhatia, S.: Nanoparticles types, classification, characterization, fabrication methods and drug delivery applications. Natural Polymer Drug Delivery Systems: Springer, 33-93 (2016).

Bhatt, R., D. Singh, A. Prakash and N. Mishra: Development, characterization and nasal delivery of rosmarinic acid-loaded solid lipid nanoparticles for the effective management of huntington's disease. Drug Deliv., 22, 931-939 (2015).

Blanco, E., H. Shen and M. Ferrari: Principles of nanoparticle design for overcoming biological barriers to drug delivery. Nat. Biotechnol., 33, 941-951 (2015)

Borges, A., V.D. Freitas, N. Mateus, I. Fernandes and J. Oliveira: Solid Lipid nanoparticles as carriers of natural phenolic compounds. Antioxidants, 9, 998 (2020). doi.org/10.3390/antiox9100998

Buchanan, B., Q. Meng, M.M. Poulin, J. Zuccolo, C.G. Azike, J. Gabriele and D.C. Baranowski: comparative pharmacokinetics and safety assessment of transdermal berberine and dihydroberberine. PLOS ONE., 13, e0194979 (2018)

Chamcheu, J.C., I.A. Siddiqui, V.M. Adhami, S. Esnault, D.J. Bharali, A.S. Babatunde, S. Adame, R.J. Massey, G.S. Wood, B.J. Longley, S.A. Mousa and H. Mukhtar: Chitosan-based nanoformulated (-)epigallocatechin-3-gallate (EGCG) modulates human keratinocyte-induced responses and alleviates imiquimod- induced murine psoriasiform dermatitis. Int. J. Nanomed., 13, 4189-4206(2018).

Chan, A.C., M. Bravo Cadena, H.E. Townley, M.D. Fricker and I.P. Thompson: Effective delivery of volatile biocides employing mesoporous silicates for treating biofilms. J. R. Soc. Interface.,14, 20160650 (2017).

Chen, R., J.E. Wulff and M.G. Moffitt: Microfluidic processing approach to controlling drug delivery properties of curcumin-loaded block copolymer nanoparticles. Mol. Pharm., 15, 4517-4128 (2018).

Chen, X., D.J. McClements, J. Wang, L. Zou, S. Deng, W. Liu, C. Yan, Y. Zhu, C. Cheng and C. Liu: Coencapsulation of (-)epigallocatechin-3-gallate and quercetin in particle-stabilized w/o/w emulsion gels: Controlled release and bioaccessibility. J. Agric. Food Chem., 66, 3691-3699(.2018).

Choi, J.G., S.Y. Kim, M. Jeong and M.S. Oh: Pharmacotherapeutic potential of ginger and its compounds in age-related neurological disorders. Pharmacol. Ther., 182, 56-69 (2018).

Dai, L., W. Zhu, C. Si and J. Lei: Nano-Ginseng for enhanced cytotoxicity against cancer cells. Int. J. Mol., 19, 627-637 (2018).

Das, S., J. Das, A. Samadder, A. Paul and A.R. Khuda-Bukhsh: Efficacy of PLGA-loaded apigenin nanoparticles in Benzo[a]pyrene and ultraviolet-B induced skin cancer of mice: mitochondria mediated apoptotic signalling cascades. Food Chem. Toxicol., 62, 670-680 (2013).

David, K.I., LR. Jaidev, S. Sethuraman and U.M. Krishnan: Dual drug loaded chitosan nanoparticles-sugar--coated arsenal against pancreatic cancer. Colloids Surf. B, Biointe., 135, 689-698 (2015).

Ding, S.M., Z.H. Zhang, J. Song, X.D. Cheng, J. Jiang and X.B. Jia: Enhanced bioavailability of apigenin via preparation of a carbon nanopowder solid dispersion. Int. J. Nanomed., 9, 2327-2333 (2014).

El-Gogary, R.I., N. Rubio, J.T.W. Wang, W.T. Al-Jamal, M. Bourgognon, H. Kafa, M. Naeem, R. Klippstein, V. Abbate, F. Leroux, S. Bals, G.V. Tendeloo, A.O. Kamel, G.A.S. Awad, N.D. Mortada and K.T. Al-Jamal: Polyethylene glycol conjugated polymeric nanocapsules for targeted delivery of quercetin to folateexpressing cancer cells in vitro and in vivo. ACS Nano., 8, 13841401 (2014).

Elgohary, M.M., M.W. Helmy, S.M. Mortada and A.O. Elzoghby: Dualtargeted nano-in-nano albumin carriers enhance the efficacy of combined chemo/herbal therapy of lung cancer. Nanomedicine, 13, 2221-2224 (2018).

El-Nahas, A.E., A.N. Allam, D.A. Abdelmonsif and A.H. El-Kamel: Silymarin-Loaded eudragit nanoparticles: formulation, characterization, and hepatoprotective and toxicity evaluation. AAPS. Pharm. Sci. Tech., 18, 3076-3086 (2017).

Encinas-Basurto, D., J. Juarez, M.A. Valdez, M.G. Burboa, S. Barbosa and P. Taboada: Targeted drug delivery via human epidermal growth factor receptor for sustained release of allyl isothiocyanate. Curr. Top. Med. Chem., 18, 1252-1260 (2018).

Ezzat, S.M., M.M. Salama, A.N. ElMeshad, M.H. Teaima and L.A. Rashad: HPLC-DAD-MS/MS profiling of standardized rosemary extract and enhancement of its anti-wrinkle activity by encapsulation in elastic nanovesicles. Arch. Pharm. Res., 39, 912$925(2016)$

Fachinetti, N., R.B. Rigon, J.O. Eloy, M.R. Sato, K.C.D. Santos and M. Chorilli: Comparative study of glyceryl behenate or polyoxyethylene 40 stearate-based lipid carriers for transresveratrol delivery: development, characterization and evaluation 
of the in vitro tyrosinase inhibition. AAPS. Pharm. Sci. Tech., 19, 1401-1409 (2018).

Fahmy, U.A.: Augmentation of fluvastatin cytotoxicity against prostate carcinoma PC3 cell line utilizing alpha lipoic-ellagic acid nanostructured lipid carrier formula. AAPS. Pharm. Sci. Tech., 19, 3454-3461 (2018).

Feng, Z., X. Yang, L. Zhang, I.A. Ansari, M.S. Khan, S. Han and Y. Feng: Ginkgolide B ameliorates oxidized low-density lipoprotein-induced endothelial dysfunction via modulating Lectin-like ox-LDLreceptor-1 and NADPH oxidase 4 expression and inflammatory cascades. Phytother. Res., 32, 2417-2427 (2018).

Ghaffari, S., F. Alihosseini, S.M.R. Sorkhabadi, S.A. Bidgoli, S.E. Mousavi, S. Haghighat, A.A. Nasab and N. Kianvash: Nanotechnology in wound healing; semisolid dosage forms containing curcumin-ampicillin solid lipid nanoparticles, in-vitro, ex-vivo and in-vivo characteristics. Adv. Pharm. Bull., 8, 395-400 (2018).

Gogoi, D., A. Pal, P. Chattopadhyay, S. Paul, RC. Deka and A.K. Mukherjee: First report of plant-derived beta-sitosterol with antithrombotic, in vivo anticoagulant, and thrombus-preventing activities in a mouse model. J. Nat. Prod., 81, 2521-2530 (2018).

Guo, C., J. Yin and D. Chen: Co-encapsulation of curcumin and resveratrol into novel nutraceutical hyalurosomes nano-food delivery system based on oligo-hyaluronic acid-curcumin polymer. Carbohydr. Polym., 181, 1033-1037(2018).

Han, Q., R. Yang, J. Li, W. Liang, Y. Zhang, M. Dong, F. Besenbacher and C. Wang: Enhancement of biological activities of nanostructured hydrophobic drug species. Nanoscale, 4, 2078-2082(2012).

Hansen, SF., SN. Sørensen, L.M. Skjolding, N.B. Hartmann and A. Baun: Revising reach guidance on information requirements and chemical safety assessment for engineered nanomaterials for aquatic ecotoxicity endpoints: recommendations from the EnvNano project. Environ. Sci. Eur., 29, 14-29 (2017).

He, H., D. Yuan, Z. Gao, D. Xiao, H. He, H. Dai, J. Peng and N. Li:. Mixed hemimicelles solid-phase extraction based on ionic liquid-coated $\mathrm{Fe} 3 \mathrm{O} 4 / \mathrm{SiO} 2$ nanoparticles for the determination of flavonoids in bio-matrix samples coupled with high performance liquid chromatography. J. Chromatogr. A., 1324,78-85(2014).

Hong, S.S., R.K. Thapa, J.H. Kim, S.Y. Kim, J.O. Kim, J.K. Kim, H.G. Choi and S.J Lim: Role of zein incorporation on hydrophobic drugloading capacity and colloidal stability of phospholipid nanoparticles. Colloids Surf B: Biointerf., 171, 514-521(2018).

Hosokawa, Y., I. Hosokawa, K. Ozaki and T. Matsuo: Honokiol and Magnolol Inhibit CXCL10 and CXCL11 production in il-27stimulated human oral epithelial cells. Inflammation, 41, 21102115(2018).

Hussein, R.M., WR. Mohamed and H.A. Omar: A neuroprotective role of kaempferol against chlorpyrifos-induced oxidative stress and memory deficits in rats via GSK3beta-Nrf2 signaling pathway. Pestic. Biochem. Physiol., 152, 29-37 (2018).

Hwang, Y.H., T. Kim, R. Kim and H. Ha: The natural product 6-Gingerol inhibits inflammation-associated osteoclast differentiation via reduction of prostaglandin E(2) levels. Int. J. Molec. Sci., 19, 20682076 (2018).

Ilk, S., N. Saglam and M. Ozgen: Kaempferol loaded lecithin/chitosan nanoparticles: preparation, characterization, and their potential applications as a sustainable antifungal agent. Artificial Cells, Nanomed. Biotechnol., 45, 907-916 (2017).

Jackson, I.L., A. Zodda, G. Gurung, R. Pavlovic, M.D. Kaytor, M.A.
Kuskowski and Z. Vujaskovic: BIO 300, a nanosuspension of genistein, mitigates pneumonitis/fibrosis following high-dose radiation exposure in the C57L/J murine model. Br. J. Pharmacol. 174, 4738-4750 (2017).

Jain, A.K., K. Thanki and S. Jain: Co-encapsulation of tamoxifen and quercetin in polymeric nanoparticles: Implications on oral bioavailability, antitumor efficacy, and drug-induced toxicity. Mol. Pharmaceutics., 10, 3459-3474 (2013).

Je, H.J., E.S. Kim, J.S. Lee and H.G. Lee: Release properties and cellular uptake in Caco-2 cells of size-controlled chitosan nanoparticles. J. Agric. Food Chem., 65, 10899-10906(2017).

Karim, R., C. Palazzo, J. Laloy, A.S. Delvigne, S. Vanslambrouck, C. Jerome, E. Lepeltier, F. Orange, J.M. Dogne, B. Evrard, C. Passirani and G. Piel: Development and evaluation of injectable nanosized drug delivery systems for apigenin. Int. J. Pharm., 532, 757-768(2017).

Khoshnevisana, K., H. Maleki, H. Samadian, S. Shahsavari, M.H. Sarrafzadeh, B. Larijani, F.A. Dorkoosh, V. Haghpanah and M.R. Khorramizadeh: Cellulose acetate electrospun nanofibers for drug delivery systems: Applications and recent advances. Carbohydrate. Polymers.,198, 131-141(2018).

Kim, E.S., J.S. Lee and H.G. Lee: Nanoencapsulation of red ginseng extracts using chitosan with polyglutamic acid or fucoidan for improving antithrombotic activities. J. Agric. Food Chem., 64, 4765-4771 (2016).

Kim, J.T., S. Barua, H. Kim, S.C. Hong, S.Y. Yoo, H. Jeon, Y. Cho, S. Gil, K. Oh and J. Lee: Absorption study of genistein using solid lipid microparticles and nanoparticles: Control of oral bioavailability by particle sizes. Biomol Ther (Seoul)., 25, 452-459 (2017).

Kim, N.W., S.Y. Kim, J.E. Lee, Y. Yin, J.H. Lee, S.Y. Lim, E.S. Kim, H.T.T. Duong, H.K. Kim, S. Kim, J.E. Kim, D.S. Lee, J. Kim, M.S. Lee, Y.T. Lim and J.H. Jeong: Enhanced cancer vaccination by in situ nanomicelle-generating dissolving microneedles. ACS Nano., 12, 9702-9713 (2018).

Kim, S.Y., H.J. Kim, M.K. Lee, S.M. Jeon, G.M. Do, E.Y. Kwon, Y.Y. Cho, D.J. Kim, K.S. Jeong, Y.B. Park and T.Y. Ha: Naringin timedependently lowers hepatic cholesterol biosynthesis and plasma cholesterol in rats fed high-fat and high-cholesterol diet. J. Med. Food., 9, 582-586 (2006).

Klumphu, P. and BH. Lipshutz: "Nok": A phytosterol-based amphiphile enabling transition-metal-catalyzed couplings in water at room temperature. J. Org. Chem., 79, 888-900 (2014).

Kühne, B.A., T. Puig, S. Ruiz-Martínez, J. Crous-Masó, M. Planas, L. Feliu, A. Cano, M.L. García, E. Fritsche, J.M. Llobet, J. GómezCatalán and $\mathrm{M}$. Barenys: Comparison of migration disturbance potency of epigallocatechin gallate (EGCG) synthetic analogs and EGCG PEGylated PLGA nanoparticles in rat neurospheres. Food Chem. Toxicol., 123, 195-204 (2019).

Lee, H., W. Shim, C.E. Kim, S.Y. Choi, H. Lee and J. Yang: Therapeutic efficacy of nanocomplex of poly (Ethylene Glycol) and catechin for dry eye disease in a mouse model. Invest. Ophthalmol. Visual Sci., 58, 1682-1691 (2017).

Li F., H. Jin, J. Xiao J, X. Yin, X. Liu, D. Li and Q. Huang: The simultaneous loading of catechin and quercetin on chitosan-based nanoparticles as effective antioxidant and antibacterial agent. Food Res. Int., 111, 351-360 (2018).

Li, Y., Z. Teng, P. Chen, Y. Song, Y. Luo and Q. Wang: Enhancement of aqueous stability of allyl isothiocyanate using nanoemulsions prepared by an emulsion inversion point method. J. Colloid. 
Interface. Sci., 438, 130-137(2015).

Lima, lad., N.M. Khalil, T.T. Tominaga, A. Lechanteur, B. Sarmento and R.M. Mainardes: Mucoadhesive chitosan-coated PLGA nanoparticles for oral delivery of ferulic acid. Artif. Cells Nanomed. Biotechnol., 46, 993-1002 (2018).

Liu, Y., Y. Fan, L. Gao, Y. Zhang and J. Yi:. Enhanced pH and thermal stability, solubility and antioxidant activity of resveratrol by nanocomplexation with alpha-lactalbumin. Food Funct., 9, 47814790 (2018).

Lou, C., H. Lu, Z. Ma, C. Liu and Y. Zhang: Ginkgolide B enhances gemcitabine sensitivity in pancreatic cancer cell lines via inhibiting PAFR/NF-small ka, CyrillicB pathway. Biomed. Pharmacother., 109, 563-572 (2019).

Luo, H., B. Jiang, B. Li, Z. Li, B.H. Jiang and Y.C. Chen: Kaempferol nanoparticles achieve strong and selective inhibition of ovarian cancer cell viability. Int. J. Nanomedicine., 7, 3951-3959 (2012).

Madureira, A.R., S. Nunes, D.A. Campos, J.C. Fernandes, C. Marques, M. Zuzarte, B. Gullón, L.M. Rodríguez-Alcalá, C. Calhau, B. Sarmento, A.M. Gomes, M.M. Pintado and F. Reis: Safety profile of solid lipid nanoparticles loaded with rosmarinic acid for oral use: In vitro and animal approaches. Int. J. Nanomed., 11, 3621-3640 (2016)

Mady, F.M. and M.A. Shaker: Enhanced anticancer activity and oral bioavailability of ellagic acid through encapsulation in biodegradable polymeric nanoparticles. Int. J. Nanomedicine., 12, 7405-7417 (2017).

Malvajerd, S.S., A. Azadi, Z. Izadi, M. Kurd, T. Dara, M. Dibaei, M.S. Zadeh, H.A. Javar and M. Hamidi: Brain Delivery of curcumin using solid lipid nanoparticles and nanostructured lipid carriers: Preparation, optimization and pharmacokinetic evaluation. ACS. Chem. Neurosci., 10, 728-739 (2019).

Meng, Q., A. Wang, H. Hua, Y. Jiang, Y. Wang, H. Mu, Z. Wu and K. Sun: Intranasal delivery of Huperzine $A$ to the brain using lactoferrinconjugated $\mathrm{N}$-trimethylated chitosan surface-modified PLGA nanoparticles for treatment of Alzheimer's disease. Int. J. Nanomedicine., 13, 705-718 (2018).

Mirhadi, E., M. Rezaee and B. Malaekeh-Nikouei: Nano strategies for berberine delivery, a natural alkaloid of Berberis. Biomed. Pharmacother., 104, 465-473 (2018).

Mohammed, H.S., Y.A. Khadrawy, T.M. El-Sherbini and H.M. Amer: Electrocortical and biochemical evaluation of antidepressant efficacy of formulated nanocurcumin. Appl. Biochem. Biotechnol., 187, 1096-1112 (2019).

Montenegro, L., C. Parenti and R. Turnaturi: Resveratrol-Loaded lipid nanocarriers: Correlation between in vitro occlusion Factor and in vivo skin hydrating effect. Pharmaceutics., 9, 58-69 (2017).

Mukherjee, A., S. Sarkar, S. Jana, S. Swarnakar and N. Das: Neuroprotective role of nanocapsulated curcumin against cerebral ischemia-reperfusion induced oxidative injury. Brain Res., 1704, 164-173 (2019).

Mukkavilli, R., C. Yang, R.S. Tanwar, A. Ghareeb, L. Luthra and R. Aneja: Absorption, metabolic stability, and pharmacokinetics of ginger phytochemicals. Molecules., 22, 553-565 (2017).

Naponelli, V., I. Ramazzina, C. Lenzi, S. Bettuzzi and F. Rizzi: Green Tea Catechins for Prostate Cancer Prevention: Present Achievements and Future Challenges. Antioxidants (Basel), 6, 26-48 (2017).

Naqvi, S., A. Panghal and S.J.S. Flora: Nanotechnology: A promising approach for delivery of neuroprotective drugs. Front Neurosci., $14,494(2020)$.
Narayan, R., U.Y. Nayak, A.M. Raichur and S. Garg: Mesoporous silica nanoparticles: A comprehensive review on synthesis and recent advances. Pharmaceutics., 10, 118-166 (2018).

Nguyen, H.Q., V.V. Chupin, D.I. Prokhorov, I.E. Chikunov, V.Y. Kovtun, R.A. Tarumov, A.N. Grebenyuk and V.I. Shvets: Creation and study of triterpenoid nanoparticles and radioprotective substance genistein. Doklady. Biochem. Biophysics. Molecu. Biol., 464, 338340(2015).

Ngwabebhoh, F., S.I. Erdagi and U. Yildiz: Pickering emulsions stabilized nanocellulosic-based nanoparticles for coumarin and curcumin nanoencapsulations: In vitro release, anticancer and antimicrobial activities. Carbohydrte. Polymers, 201, 317-328 (2018).

Oehlke, K., D. Behsnilian, E. Mayer-Miebach, P.G. Weidler and R. Greiner: Edible solid lipid nanoparticles (SLN) as carrier system for antioxidants of different lipophilicity. PloS One., 12, e0171662 (2017).

Pal, M.K., S.P. Jaiswar, A. Dwivedi, S. Goyal, V.N. Dwivedi, A.K. Pathak, V. Kumar, P.L. Sankhwar and R.S. Ray: Synergistic Effect of Graphene Oxide Coated Nanotinsed Apigenin with Paclitaxel (GO-NA/PTX): A ROS Dependent Mitochondrial Mediated Apoptosis in Ovarian Cancer. Anticancer Agents Med. Chem., 17, 1721-1732 (2017).

Pandey, S.K., D.K. Patel, R. Thakur, D.P. Mishra, P. Maiti and C. Haldar: Anti-cancer evaluation of quercetin embedded PLA nanoparticles synthesized by emulsified nanoprecipitation. Int. J. Biol. Macromol., 75, 521-529 (2015).

Panpipat, W., M. Dong, X. Xu and Z. Guo: Thermal properties and nanodispersion behavior of synthesized beta-sitosteryl acyl esters: a structure-activity relationship study. J. Coll. Interface Sci., 407, 177-186 (2013).

Papay, Z.E., A. Kosa, B. Boddi, Z. Merchant, I.Y. Saleem, M. Zariwala, I. Klebovich, S. Somavarapu and I. Antal: Study on the Pulmonary Delivery System of Apigenin-Loaded Albumin Nanocarriers with Antioxidant Activity. J. Aerosol Med. Pulm. Drug Delivery., 30, 274$288(2017)$

Parashar, P., M. Rathor, M. Dwivedi and S.A. Saraf: Hyaluronic Acid Decorated Naringenin Nanoparticles: Appraisal of Chemopreventive and Curative Potential for Lung Cancer. Pharmaceutics, 10, 33-55 (2018).

Park, S.H., J.H. Sung, E.J. Kim and N. Chung: Berberine induces apoptosis via ROS generation in PANC-1 and MIA-PaCa2 pancreatic cell lines. Braz. J. Med. Biol. Res., 48, 111-119(2015).

Penalva, R., J. Morales, C.J. Gonzalez-Navarro, E. Larrañeta, G. Quincoces, I. Peñuelas and J.M. Irache: Increased Oral Bioavailability of resveratrol by its encapsulation in casein nanoparticles. Int. J. Mol. Sci., 19, 2816-2833 (2018).

Pimple, S., A.S. Manjappa, M. Ukawala and R.S. Murthy: PLGA nanoparticles loaded with etoposide and quercetin dihydrate individually: in vitro cell line study to ensure advantage of combination therapy. CancerNanotechnol., 3, 25-36 (2012).

Ponnulakshmi, R., B. Shyamaladevi, P. Vijayalakshmi and Selvaraj: In silico and In vivoanalysis to identify the antidiabetic activity of beta sitosterol in adipose tissue of high fat diet and sucrose induced type-2 diabetic experimental rats. Toxicol. Mech. Methods., 29, 276-290 (2019).

Pool, H., R. Campos-Vega, M.G. Herrera-Hernández, P. García-Solis, T. García-Gasca, I.C. Sánchez, G. Luna-Bárcenas and H. VergaraCastañeda: Development of genistein-PEGylated silica hybrid nanomaterials with enhanced antioxidant and antiproliferative 
properties on HT29 human colon cancer cells. Am. J. Transl. Res., 10,2306-2323 (2018).

Ramalingam, G., K.V. Saravanan, T.K. Vizhi, M. Rajkumar and K. Baskar: Synthesis of water-soluble and bio-taggable CdSe@ ZnS quantum dots. RSCAdv., 8, 8516-8527 (2018).

Rezaei-Sadabady, R., A. Eidi, N. Zarghami and A. Barzegar: Intracellular ROS protection efficiency and free radical-scavenging activity of quercetin and quercetin-encapsulated liposomes. Artificial Cells, Nanomed. Biotechnol., 44, 128-134 (2016).

Sapino, S., E. Ugazio, L. Gastaldi, I. Miletto, G. Berlier, D. Zonari and S. Oliaro-Bosso: Mesoporous silica as topical nanocarriers for quercetin: Characterization and in vitro studies. Eur. J. Pharm. Biopharm., 89, 116-125(2015).

Sarrica, A., N. Kirika, M. Romeo, M. Salmona and L. Diomede: Safety and toxicology of magnolol and honokiol. Planta Med., 84, 11511164 (2018).

Serini, S., R. Cassano, P.A. Corsetto, A.M. Rizzo, G. Calviello and S. Trombino: Omega-3 PUFA loaded in resveratrol-based solid lipid nanoparticles: physicochemical properties and antineoplastic activities in human colorectal cancer cells in vitro. Int. J. Mol. Sci., 19, 586-605 (2018).

Sharma, G., J. Park, A.R. Sharma, J.S. Jung, H. Kim, C. Chakraborty, D.K. Song, S.S. Lee and J.S. Nam: Methoxy poly(ethylene glycol)poly (lactide) nanoparticles encapsulating quercetin act as an effective anticancer agent by inducing apoptosis in breast cancer. Pharma. Res., 32, 723-735 (2015).

Sharma, R., S.Y. Kim, A. Sharma, Z. Zhang, S.P. Kambhampati, S. Kannan and R.M. Kannan: Activated microglia targeting dendrimer-minocycline conjugate as therapeutics for neuroinflammation. Bioconjug. Chem., 28, 2874-2886 (2017).

Shen, Y., B. Cao, N.R. Snyder, K.M. Woeppel, J.R. Eles and X.T. Cui: ROS responsive resveratrol delivery from LDLR peptide conjugated PLA-coated mesoporous silica nanoparticles across the blood-brain barrier. J. Nanobiotechnol., 16, 1-17 (2018).

Shin, S.W., W. Jung, C. Choi, S.Y. Kim, A. Son, H. Kim, N. Lee and H.C. Park: Fucoidan-manganese dioxide nanoparticles potentiate radiation therapy by co-targeting tumor hypoxia and angiogenesis. Mar. Drugs, 16, 510 (2018).

Singh, P., Y.J. Kim, H. Singh, S. Ahn, V. Castro-Aceituno and D.C. Yang: In situ preparation of water-soluble ginsenoside Rh2-entrapped bovine serum albumin nanoparticles: In vitro cytocompatibility studies. Int. J. Nanomedicine., 12, 4073-4084 (2017).

Singh, A.B., H. Li, C.F.K. Kan, B. Dong, M.R. Nicolls and J. Liu: The critical role of mRNA destabilizing protein heterogeneous nuclear ribonucleoprotein $d$ in $3^{\prime}$ untranslated region-mediated decay of low-density lipoprotein receptor mRNA in liver tissue. Arterioscler Thromb. Vasc. Biol., 34, 8-16 (2014).

Singh, M.K., D. Pooja, H.G. Ravuri, A. Gunukula, H. Kulhari and R. Sistla: Fabrication of surfactant-stabilized nanosuspension of naringenin to surpass its poor physiochemical properties and low oral bioavailability. Phytomedicine, 40, 48-54 (2018).

Sistanipour, E., A. Meshkini and H. Oveisi: Catechin-conjugated mesoporous hydroxyapatite nanoparticle: A novel nanoantioxidant with enhanced osteogenic property. Colloids Surf. B, Biointerfaces., 169, 329-339 (2018).

Suktham, K., T. Koobkokkruad, T. Wutikhun and S. Surassmo: Efficiency of resveratrol-loaded sericin nanoparticles: Promising bionanocarriers for drug delivery. Int. J. Pharm., 537, 48-56 (2018).

Sun, M., S. Nie, X. Pan, R. Zhang, Z. Fan and S. Wang: Quercetinnanostructured lipid carriers: characteristics and anti-breast cancer activities in vitro. Colloids. Surf. B. Biointerfaces., 113, 1524(2014).

Tang, P., Q. Sun, H. Yang, B. Tang, H. Pu and L. Li: Honokiol nanoparticles based on epigallocatechin gallate functionalized chitin to enhance therapeutic effects against liver cancer. Int. J. Pharm., 545, 74-83(2018).

Tzeng, C.W., F.L. Yen, T.H. Wu, H.H. Ko, C.W. Lee, W.S. Tzeng and C.C. Lin: Enhancement of dissolution and antioxidant activity of kaempferol using a nanoparticle engineering process. J. Agric. Food Chem., 59, 5073-5080 (2011).

Venkatesan, R., L. Subedi, E.J. Yeo and Kim: Lactucopicrin ameliorates oxidative stress mediated by scopolamine-induced neurotoxicity through activation of the NRF2 pathway. Neurochemistry. Int., 99,133-146 (2016).

Venkatesan R., Y. Park, T.H. Lee, S. Kim: Gnetol, a Resveratrol Derivative Ameliorates Malathion-Induced Neurotoxicity through Modulating Lysosomal Membrane Permeabilization in N2a Cells. J Alzheimers Dis Parkinsonism., 7, 21610460.1000388 (2017).

Venkatesan, R., E. Ji and SY. Kim: Phytochemicals that regulate neurodegenerative disease by targeting neurotrophins: a comprehensive review. Bio.Med. Res., Int., 2015, Article ID 814068, pp. 22 (2015). https://doi.org/10.1155/2015/814068

Wang, E.C. and A.Z. Wang: Nanoparticles and their applications in cell and molecular biology. Integr. Biol. (Camb). 6, 9-26 (2014).

Wang, Y., B. Wen, H. Yu, D. Ding, J. Zhang, Y. Zhang, L. Zhao and W. Zhang: Berberine Hydrochloride-Loaded Chitosan Nanoparticles Effectively Targets and Suppresses Human Nasopharyngeal Carcinoma. J. Biomed. Nanotechnol., 14, 1486-1495(2018).

Wang, Y., S. Wang, C.K. Firempong, H. Zhang, M. Wang, Y. Zhang, Y. Zhu, J. Yu and X. Xu: Enhanced Solubility and Bioavailability of Naringenin via Liposomal Nanoformulation: Preparation and In Vitro and In Vivo Evaluations. AAPS. Pharm. Sci. Tech., 18, 586594 (2017)

Weiss-Angeli, V., F.S. Poletto, S.L. de Marco, M. Salvador, N.P. da Silveira, S.S. Guterres and A.R. Pohlmann: Sustained antioxidant activity of quercetin-loaded lipid-core nanocapsules. J. Nanosci. Nanotechnol., 12, 2874-2880 (2012).

Wolff-Holz, E., K. Tiitso, C. Vleminckx and M. Weise: Evolution of the EU biosimilar framework: Past and future. BioDrugs, 33, 1-14 (2019).

Yan, X.Q., Y.L. Shi, Q.F. Jiang, G.F. Ping and Z.J. Deng: Design of amphiphilic PCL-PEG-PCL block copolymers as vehicles of Ginkgolide B and their brain-targeting studies. J. Biomater. Sci. Polymer., 28, 1497-1510 (2017).

Zainon, S.N.M. and W.H. Azmi: Recent progress on stability and thermophysical properties of mono and hybrid towards green nanofluids. Micromachines (Basel). 12, 176 (2021).

Zhang, S., J. Liu, B. Ge, M. Du, L. Fu, Y. Fu and Q. Yan: Enhanced antitumor activity in A431 cells via encapsulation of 20(R)ginsenoside Rg3 in PLGA nanoparticles. Drug Dev. Ind. Pharm., 43, 1734-1741(2017). 